\title{
Brain metabolism after recurrent insulin induced hypoglycaemic episodes: a PET study
}

Hugues Chabriat, Claude Sachon, Michèle Levasseur, André Grimaldi, Sabina Pappata, Didier Rougemont, Marie Cécile Masure, Anne De Recondo, Yves Samson

\begin{abstract}
Neuropsychological testing was carried out and the rate of oxygen metabolism in the brain was measured by PET in 15 highly selected patients with type 1 diabetes. The aim was to investigate the impact on the brain of hypoglycaemic comas resulting from insulin treatment. No significant difference was found between nine patients with a history of more than 10 hypoglycaemic comas and six others who denied any history of such events. These data suggest that intensified insulin treatment, although increasing the frequency of hypoglycaemic coma, may not always be harmful for the brain. This may be explained by the limited duration of hypoglycaemic coma induced by conventional insulin treatment.
\end{abstract}

$(\Im$ Neurol Neurosurg Psychiatry 1994;57:1360-1365)

Accurate glycaemia control by insulin treatment may prevent or delay most of the long term complications of diabetes mellitus. ${ }^{1}$ As a consequence, hypoglycaemia is now the most frequent morbid event in insulin dependent diabetic patients as the optimal glycaemic control increases the risk of hypoglycaemia two to threefold. ${ }^{2}$ Some $10-25 \%$ of patients with type 1 diabetes have at least one episode of severe hypoglycaemia, often with seizure or coma, in a given year. ${ }^{3}$ This raises the problem of the long term impact of insulin induced hypoglycaemic episodes on the brain. ${ }^{4}$ Several neuropsychological studies have previously considered this point. Some results, but not all, are consistent with a cumulative cognitive impairment after recurrent hypoglycaemic episodes. ${ }^{2}$ To further investigate this issue, we studied the cerebral metabolic rate of oxygen $\left(\mathrm{CMRO}_{2}\right)$, brain $M R I$, and cognitive function in highly selected patients with insulin dependent diabetes. We compared patients with a history of recurrent hypoglycaemic comas with patients who denied any history of such events.

\section{Materials and methods}

PATIENTS

Fifteen patients with insulin dependent diabetes gave their informed consent to participate in the study. They were selected according to the criteria: (a) lack of macro- angiopathic complications of diabetes based on normal arterial blood pressure, no history of cerebrovascular disease, normal CT, and normal vascular examination by cervical and transcranial doppler; (b) lack of major microangiopathy based on normal visual acuity with no proliferative retinopathy and albuminuria less than $300 \mathrm{mg} / 24 \mathrm{~h}$; (c) lack of postural hypotension, peripheral sensory or motor deficit; (d) either a history of more than 10 hypoglycaemic comas or no history of severe hypoglycaemia (requiring assistance from others).

Nine patients (group HC) reported more than 10 hypoglycaemic comas (episodes of coma rapidly relieved by treatment with glucagon or intravenous glucose). Detailed history concerning these events was recorded on the basis of interviews of patients and witnesses (spouses or equivalent), and on medical records. In all of these patients, hypoglycaemia unawareness (failure to recognize autonomic warning symptoms or lack of symptoms before development of neuroglycopenia ${ }^{5}$ ) has been previously recorded in hospital. This condition is known to increase the risk of hypoglycaemia 25 -fold and to cause severe hypoglycaemic insults. ${ }^{5-6}$ The exact number of episodes experienced in a lifetime was known in six subjects (range 10-20) but was not precisely determined in three subjects because of their high number (range $\approx$ 50-100). In each patient, an apparently complete clinical recovery from hypoglycaemic insults was always seen within less than one hour of dextrose or glucagon injection and none had previously required admission to an intensive care unit.

Six patients without any history of hypoglycaemic comas (group NHC) were similarly investigated. Hypoglycaemia unawareness had never been documented in these patients.

Groups HC and NHC did not differ in mean age (mean (SE)) (range): $47 \cdot 6$ (4.4) (30 to 71$) v 42 \cdot 83(7 \cdot 72)(20-63)$ years), educational level, duration of diabetes $(19.56(4.06)$ (3-38) $v 11.33(2 \cdot 85)(2-21)$ years), daily dose of insulin $(34.8(3.38)(17 \cdot 5-45) v 44 \cdot 1$ $(8 \cdot 6)(12-75) \mathrm{U})$, or glycosylated haemoglobin concentration $(7 \cdot 24(0.45)(4 \cdot 8-9 \cdot 7) v$ $7.05(0.33)(6 \cdot 3-7 \cdot 9) \%$ : normal range $4-5 \cdot 6 \%)$.

For all patients, the neuropsychological testing was performed under their usual regimen of insulin treatment during the week preceding the PET study and when they were admitted to hospital. All of them underwent 
frequent blood glucose estimations in the 24 hours before testing either neuropsychologically or with PET. No episodes of hypoglycaemia were noted 24 hours before cognitive or PET examination.

\section{NEUROPSYCHOLOGICAL TESTS}

Blood glucose concentrations were measured with a glucometer immediately before and after testing. The values ranged from 6 to 11 $\mathrm{mmol} / \mathrm{l}$.

The neuropsychological examination included tests aimed to assess global efficiency, attention, memory, and verbal fluency. ${ }^{7}$ These tests are highly sensitive and can be used in groups of small size. ${ }^{7}$

Global efficiency was screened by the trail making test and the letter cancellation test. The trail making test assesses visual scanning and motor planning on motor speed and attention. This test is given in two parts, A and $B$. In part $A$, the patient must connect a series of randomly arrayed numbers in numerical sequence $(1-2-3 \ldots$. . In part $B$, numbers and letters must be connected in alternating sequence $(1-\mathrm{A}, 2-\mathrm{B}, 3-\mathrm{C}$. . .). We scored this test by the time needed to complete the task. ${ }^{7}$ The letter cancellation test requires visual selectivity at fast speed on a repetitive motor task. Subjects are presented with letters and must cancel one given letter as fast as possible. The score is dependent on the time taken for the task and the percentage of errors.

The Stroop word task is a classical attentional task. Although the type of brain circuit used in attention is still debatable, recent PET studies have suggested that this task mainly involves the cingulate gyrus and the frontal cortex..$^{8-9}$ The test requires the subject to read or name the colours from a list under three conditions: (a) read colour names printed in black ink; (b) name the colours presented in coloured dots; $(c)$ name the colour of ink in which incongruous colour names are printed (for example, "RED" printed in green ink, the subject names the ink colour "green"). The time elapsed is evaluated for each task. This test provides a measure of interference of word reading on colour naming.

Memory tests included the digit span and auditory verbal learning test. The digit span of the Wechsler adult intelligence scale (WAIS) verbal scale explores the immediate repetition of growing series of digits in direct order (A) and in reverse order (B). This is a test of attention and short term memory. The auditory-verbal learning test ${ }^{7}$ consists of five presentations of a list of 15 words with immediate recall and a single delayed recall 30 minutes later. Words are read at the rate of one per second. We scored the mean number of words recalled at the five first recall trials and the number of words recalled at the delayed trial.

Verbal fluency was assessed with the lexical fluency test. This test consists of the oral production of the maximum number of words beginning with a designated letter during one minute. The total number of words given was used as the score. Studies with PET suggest that the left frontal lobe and cingulate gyrus are involved during this task. ${ }^{10}$

\section{MAGNETIC RESONANCE IMAGING}

Cerebral MRI was performed on the same day as the PET study on a superconducting 0.5 tesla General Electric imager. Ten to 12 contiguous sections (5 $\mathrm{mm}$ thickness) were acquired parallel to the orbitomeatal line. Head positioning was verified with laser beams. Cutaneous landmarks were drawn to allow an exact repositioning of the head during the PET study. T1 $(\mathrm{TR}=480 \mathrm{~ms}$; TE = $12 \mathrm{~ms}$ ) and T2 (TR $=2300-2900 \mathrm{~ms} ; \mathrm{TE}=$ $100 \mathrm{~ms}$ ) weighted sequences were obtained for all subjects. Images were independently analysed by a neurologist blinded to the age and state of the patients. Areas of increased signal intensity were scored on T2 weighted images using the scheme reported by Bowen et al. ${ }^{11}$ The degree of cortical atrophy was ranked based on the sulci aspect on the $T 1$ weighted MR images obtained at the orbitomeatal line $+40 \mathrm{~mm}$ by three of us (HC, ML, YS) who were blinded to the subjects' condition. The final rank was based on the sum of the three scores. ${ }^{12}$

\section{POSITRON EMISSION TOMOGRAPHY}

The subjects continued their usual regimen before the PET study. The study started at 10 $00 \mathrm{am}$, after the morning insulin injection and breakfast between 730 and $830 \mathrm{am}$. Cerebral blood flow (CBF), oxygen consumption rate $\left(\mathrm{CMRO}_{2}\right)$, cerebral blood volume (CBV), and oxygen extraction fraction (OEF) were measured with the ${ }^{15} \mathrm{O}$ inhalation method using successive inhalation of $\mathrm{C}^{15} \mathrm{O}_{2},{ }^{15} \mathrm{O}_{2}$, and $\mathrm{C}^{15} \mathrm{O} .{ }^{13-14}$ The positron camera used was a 4 ring LETI-TTVO1 time of flight camera with both slice thickness and lateral resolution of $12 \mathrm{~mm}$. Seven slices were obtained (four direct and three cross sections with an interslice space of $3 \mathrm{~mm}) .{ }^{15}$ Correction for attenuation was carried out with ${ }^{68} \mathrm{Ge}-{ }^{68} \mathrm{Ga}$ transmission scans before gas inhalation. The studies were performed with the patients at rest, their eyes closed, and their heads positioned as in MRI, using the cutaneous landmarks and a crossed laser beam system. The lowest slice was located $10 \mathrm{~mm}$ above and parallel to the orbitomeatal line. During each of the three successive scans, blood samples were withdrawn from a radial artery catheter to measure the ${ }^{15} \mathrm{O}$ radioactivity (two samples) in whole blood and plasma and the $\mathrm{PaO}_{2}$, $\mathrm{PaCO}_{2}, \mathrm{pH}$, haematocrit, haemoglobin, and glucose values. The $\mathrm{CMRO}_{2}$ was calculated with correction for the intravascular labelled oxyhaemoglobin using the $\mathrm{C}^{15} \mathrm{O}$ steady state image (CBV). ${ }^{16}$

Four slices were used for data analysis. They corresponded respectively to the "cerebellar cut" (orbitomeatal line $+10 \mathrm{~mm}$ ), "basal ganglia cut" (orbitomeatal line +40 $\mathrm{mm}$ ), "low centrum semiovale cut" (orbitomeatal line $+55 \mathrm{~mm}$ ) and "high centrum semiovale cut" (orbitomeatal line $+70 \mathrm{~mm}$ ). A standardised and already validated method for the regional cortical data analysis was 
Regional $\mathrm{CMRO}_{2}$ indices in HC group (solid circles) and NHC group (open circles) in large lobar $(A)$ and MRI based smaller

(B) cortical regions and in subcortical regions $(C)$.

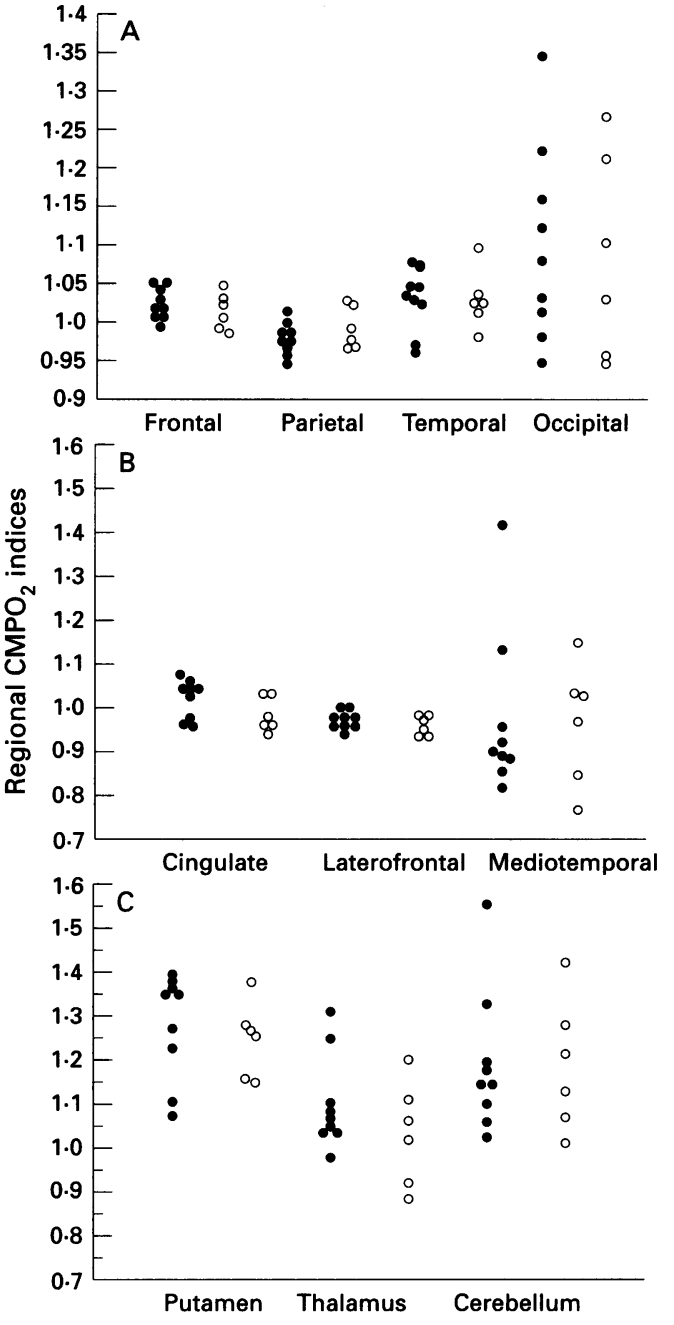

used. ${ }^{17}$ Circular regions of interest of $3 \mathrm{~cm}^{2}$ were positioned on the $\mathrm{CBF}$ images along the cortical rim of one cerebral hemisphere tangentially to each other and to an external isocontour of $30 \%$ of maximal activity. These regions of interest were then mirror copied on the opposite hemisphere. They were pooled in six large lobar regions corresponding to the frontal, temporal, parietal, and occipital cortex. Lobar limits were based on the atlas of Matsui and Hirano ${ }^{18}$ and individual MRI. In addition, putaminal, thalamic, mediotempo- ral, and anterior cingulate regions of interest were drawn on MRI and superimposed on the corresponding $\mathrm{CBF}$ images after verifying that the contour of the brain obtained on MRI corresponded to the $30 \%$ isocontour of $\mathrm{CBF}$ images at the same levels. All regions of interest were subsequently translated on the corresponding $\mathrm{CMRO}_{2}, \mathrm{OEF}$, and CBV images.

\section{STATISTICS}

The Mann-Whitney U test was used to compare the ranking for cortical atrophy and the scores obtained on MRI signal abnormalities between the groups. The same test was used to compare each score of the neuropsychological assessment between $\mathrm{HC}$ and NHC groups.

A two tailed unpaired Student's $t$ test with appropriate Bonferroni correction was used for PET data analysis. Mean cortical absolute values of $\mathrm{CBF}, \mathrm{CMRO}_{2}, \mathrm{OEF}, \mathrm{CBV}$, and $\mathrm{CBF} / \mathrm{CBV}$ and regional "metabolic indices" obtained by dividing each regional $\mathrm{CMRO}_{2}$ values by the mean cortical $\mathrm{CMRO}_{2}$ were compared between the groups.

\section{Results}

MAGNETIC RESONANCE IMAGING

The ranking obtained for cortical atrophy did not show any difference between the two groups. Hence, cortical atrophy was visually estimated as minimal or absent in all patients, except one who had moderate sulcal enlargement.

The scores obtained for MRI signal abnormalities did not differ significantly between the two groups. Also, the scores were within the normal range according to the criteria of Bowen et al. ${ }^{11}$ No signal abnormality was detected on T1 images. No signal abnormality was seen on T2 images in the NHC group. Only a few punctate hypersignals, always less than $2 \mathrm{~mm}$ in size, were found and occurred in four of nine HC group patients. These hypersignals were located in the periventricular area in one case (two lesions in one 71 year old patient) and outside the periventricular domain in four cases (10 lesions in the 71 year old; three, three and one lesions respectively in the other cases). Similar signal abnormalities are often seen in normal elderly subjects.

NEUROPSYCHOLOGICAL TESTS

The neuropsychological testing did not show any statistically significant difference between HC and NHC groups (table 1).

POSITRON EMISSION TOMOGRAPHY

The PET results did not show any significant difference between the $\mathrm{HC}$ and NHC groups. The mean cortical values of $\mathrm{CBF}, \mathrm{CMRO}_{2}$, $\mathrm{OEF}, \mathrm{CBV}$, and $\mathrm{CBF} / \mathrm{CBV}$ did not differ between the groups (table 2); these values did not differ significantly from the corresponding values obtained in six healthy subjects of similar mean age who had neither MRI nor glucose measurement and who were studied during the same year in our centre. No difference was found between the HC and NHC 
Table 2 Mean absolute values of $\mathrm{CBF}, \mathrm{CMRO}, \mathrm{OEF}, \mathrm{CBV}$, and $\mathrm{CBF} / \mathrm{CBV}$ calculated for the whole cortex in HC and NHC groups

\begin{tabular}{lcc}
\hline & Group HC & Group NHC \\
\hline CBF $(\mathrm{ml} / 100 \mathrm{ml} / \mathrm{min})$ & $31 \cdot 1(24 \cdot 33-38 \cdot 21)$ & $31 \cdot 2(22 \cdot 65-39 \cdot 53)$ \\
$\mathrm{CMRO}_{2}(\mathrm{ml} / 100 \mathrm{ml} / \mathrm{min})$ & $2 \cdot 41(1 \cdot 92-2 \cdot 62)$ & $2 \cdot 27(2 \cdot 05-2 \cdot 77)$ \\
OEF $(\%)$ & $0 \cdot 46(0 \cdot 32-0 \cdot 52)$ & $0 \cdot 42(0 \cdot 35-0 \cdot 57)$ \\
$\mathrm{CBV}(\mathrm{ml} / 100 \mathrm{ml})$ & $3 \cdot 38(2 \cdot 58-5 \cdot 17)$ & $3 \cdot 49(3 \cdot 03-3 \cdot 66)$ \\
$\mathrm{CBF} / \mathrm{CBV}(1 / \mathrm{min})$ & $9 \cdot 93(6 \cdot 13-12 \cdot 34)$ & $9 \cdot 23(7 \cdot 35-12 \cdot 32)$ \\
\hline
\end{tabular}

Values in parentheses are $95 \%$ confidence intervals. $\mathrm{CBF}=$ cerebral blood flow; $\mathrm{CMRO}_{2}=$ oxygen consumption rate; $\mathrm{OEF}=$ oxygen extraction fraction; $\mathrm{CBV}=$ cerebral blood volume

groups for the different regional $\mathrm{CMRO}_{2}$ indices (figure). During the PET study, the two groups did not differ in glycaemia $(9.01$ (95\% confidence interval 5.3-15.2) $v 11.03$ $(7 \cdot 68-14 \cdot 32) \mathrm{mmol} / \mathrm{l})$, packed cell volume $(42$ $(39-46) \% \quad v \quad 42 \quad(37-46) \%$, pH $\quad(7 \cdot 39$ $(7 \cdot 38-7 \cdot 40)$ v 7.39 $(7 \cdot 38-7 \cdot 40)$ or $\mathrm{pCO}_{2}$ $(39 \cdot 24(35 \cdot 95-42 \cdot 53) v 39 \cdot 76(36 \cdot 85-42 \cdot 68)$ $\mathrm{mm} \mathrm{Hg}$ ).

\section{Discussion}

The aim of this study was to determine whether hypoglycaemic comas resulting from insulin treatment in diabetes can harm the brain. We did not find any neuropsychological, MRI, or PET evidence to support such a detrimental role for these comas. By contrast, several authors previously reported deleterious consequences of repeated severe hypoglycaemic insults on cognitive function in patients with insulin dependent diabetes. Wredling et al found that type 1 diabetic patients with recurrent severe hypoglycaemia scored lower in tests of motor ability, short term and associative memory, and some visuospatial tasks. ${ }^{19}$ They suggested that such a pattern might indicate a frontal dysfunction. These findings were in line with those of Bale et $a l$ and Sachon et al who showed that patients with recurrent severe hypoglycaemia performed poorly in tests of auditory learning and short term memory. ${ }^{20-21}$ More recently, Langan et al reported significant correlations between the frequency of recurrent severe hypoglycaemia and measurements of the performance IQ of the Wechsler adult intelligence scale and of inspection time and reaction time. ${ }^{22}$ Our negative results may be related to the small size of our sample ( $\beta$ type statistical error). We consider this unlikely, however, for the following reasons. The median and mean values of the neuropsychological scores were similar in both groups. In a recent three year prospective study, Reichard et al did not find any effect of intensified insulin treatment on cognitive function despite more frequent recurrent severe hypoglycaemia. ${ }^{23}$ Because the measurement of brain metabolism has been shown to have high sensitivity for detection of cerebral abnormalities in small series of patients with ischaemia, ${ }^{24}$ dementia, ${ }^{25-26}$ or epilepsy, ${ }^{27}$ the lack of metabolic abnormality in our study further supports the idea that recurrent hypoglycaemic comas can leave the brain undamaged in patients with insulin dependent diabetes. It may well be that this is true, however, only in the absence of angiopathic com- plications as our study was designed to exclude these. Indeed, Ryan et al recently reported that only in patients with insulin dependent diabetes with neuropathy does recurrent hypoglycaemia worsen intellectual performance. ${ }^{28}$

Multiple brain injuries have been reported in neuropathological studies after hypoglycaemic comas. Kalimo et al found an extensive necrotising injury with gliosis in the cerebral cortex, amygdala, hippocampus, putamen, globus pallidus, and thalamus in a patient who died after two months in a posthypoglycaemic coma. ${ }^{29}$ Moersh et al reported two patients with insulinomas who died after a prolonged hypoglycaemia. ${ }^{30}$ Both of these patients had neuronal degeneration in the cortex and basal nuclei. Diffuse and widespread brain damage has also been reported after fatal hypoglycaemia in babies. ${ }^{31}$ In another study, Iwai et al reported a periventricular hypodensity and pronounced contrast enhancement of the cortex with CT in one patient in a persistent vegetative state after insulin suicide. ${ }^{32}$ In all these cases, recovery after the resolution of hypoglycaemia usually took several hours or days and was most often incomplete, leaving residual brain dysfunction as severe motor deficits, dementia, or prolonged coma, followed by death. Such hypoglycaemic comas were profound, and of a very long duration, because they resulted from insulinomas, insulin suicide, or overdose of long acting hypoglycaemic agents. ${ }^{33-34}$ Hence, the lack of persistent cognitive, MRI, and metabolic alterations in our patients may be the result of therapeutic doses of insulin with time limited hypoglycaemic effects, and, perhaps, of maintained counter-regulatory hormonal secretions. ${ }^{35}$

The striking importance of the duration of hypoglycaemia is supported by experimental studies, which show a clear relation between the duration of the insulin induced hypoglycaemic comas and the severity of the resultant brain damage. Auer et al showed that the irreversible brain damage after hypoglycaemia in rats required at least one hour of flat EEG. ${ }^{36}$ Light and electron microscopic examination showed that after this duration, brain damage affected only the superficial laminae of the neocortex (chiefly layer 2), the hippocampal gyri, and the striate nucleus. The neuronal changes in the neocortical layers 4 and 6 were reversible. ${ }^{37-39}$ Furthermore, when this delay had passed, the brain damage correlated with the EEG isoelectric time. ${ }^{40}$ In monkeys, 57 minutes of absent evoked potentials (corresponding to 10-20 minutes of flat EEG) were not enough to produce brain damage. ${ }^{41}$ Our data support the view that a "brain damage free period" also exists during hypoglycaemic comas in humans. Whereas we found that this period was less than one hour in most of our cases, a more exact estimate was impossible as the duration of the comas could not always be precisely ascertained.

The prolonged brain resistance to hypoglycaemia contrasts with the immediate brain damage caused by hypoxia ${ }^{17-42}$ or ischaemia. ${ }^{43}$ 
This suggests that endogenous non-glucose fuels may be used by the brain to maintain the cellular energy state for a limited period. In support of this, the brain oxygen consumption was found to be maintained close to normal values during 15 minutes of flat $E_{E G}^{44}$ whereas the glucose to oxygen utilisation ${ }^{44}$ was greatly reduced in hypoglycaemic rats. Furthermore, the ATP level only dropped to $30 \%$ during this period, contrasting with the ATP decrease of $95 \%$ during hypoxia. ${ }^{45-47}$ In humans, Della Porta et al also found that the brain oxygen consumption underwent a slight but insignificant diminution during the sakel insulin treatment, whereas the cerebral glucose utilisation decreased progressively by more than $80 \%$. This result was obtained 90 minutes after insulin injection, during a state of somnolence, and four to five hours later, during a profound coma. ${ }^{48}$ Thus our results suggest that this adaptative metabolic state may effectively protect the human brain during short insulin induced hypoglycaemic events.

In summary, the combined MRI, PET, and neuropsychological data obtained in a small but highly selected group of patients indicate that the brain is resistant to the hypoglycaemia that may occur during insulin treatment. These data may be helpful in the design of large clinical studies to investigate the risk:benefit ratio of intensified insulin treatment.

We are grateful for the technical assistance of $M$ Ottaviani M Crouzel, and N Boullais. This study was supported in part by $\mathrm{La}$ Fondation pour la Recherche Médicale.

1 Reichard P, Rosenqvist U. Nephropathy is delayed by intensified insulin treatment in patients with insulin intensified insulin treatment in patients with insulinMed 1989;226:81-7.

2 The DCCT Research group. Epidemiology of severe hypoglycaemia in the diabetes and complication trial fAMA 1991;90:450-9.

3 Cryer PE, Binder C, Bolli GB, Cherrington A, Gale EAM. Sherwin RS. Hypoglycaemia in diabetes. Conference summary. Diabetes 1989;38:1193-9.

4 Moradian AS. Diabetic complications of the central nervous system. Endocr Rev 1988;3:346-56.

5 Gerich JE, Mokan M, Veneman T, Korytkowski M, Mitrakou A. Hypoglycaemia unawareness. Endocr Rev 1991;14:356-71.

6 Cryer PE. Perspective in diabetes. Iatrogenic hypoglycaemia as a cause of hypoglycaemia-associated autonomic failure in IDDM. A vicious cycle. Diabetes 1992; 41:255-60.

7 Lezak MD. Neuropsychological assessment. A compendium of tests and assessment techniques. New York: Oxford tests and assessment tech

8 Dao-Castellana MH, Samson Y, Legault F, Martinot JL, Holler A, Abin HJ, et al. Frontal glucose metabolism in chronic alcoholism. Society of Neuroscience Abstract 1991;17:359.

9 Pardo JV, Pardo P, Janer K, Raichle M. The anterior cingulate cortex mediates processing selection in the Stroop attentional conflict paradigm. Proc Natl Acad Sci USA 1990;87:256-9.

10 Frith CD, Friston KJ, Liddle PF, Frackowiak RSI. A PET study of word finding. Neuropsychologia 1991;12: $1137-48$.

11 Bowen BC, Barker WW, Lowenstein DA, Sheldon J, Duara $\mathrm{R}$. MR signal abnormalities in memory disorder and dementia. $A \mathscr{\jmath} R$ Am $\mathcal{F}$ Roentgenol 1990;154:1285-92.

12 Fiorelli M, Duboc D, Mazoyer BM, Blin J, Eymard B, Fardeau $M$, et al. Decreased cerebral glucose utilization in myotonic dystrophy. Neurology 1992;42:91-4.

13 Frackowiak RSJ, Lenzi GL, Jones T, Heather JD. Quantitative measurement of regional cerebral blood flow and oxygen metabolism in man using ${ }^{15} \mathrm{O}$ and positron emission tomography: theory, procedure and positron emission tomography: theory, procedure and normal values. $J$ our

14 Lebrun-Grandié P, Baron JC, Soussaline F, Loch C Sastre J, Bousser MG. Coupling between regional blood flow and oxygen utilization in the normal brain: a study with positron emission tomography and oxygen 15. Arch Neurol 1983;40:230-6.

15 Soussaline F, Campagnolo R, Verrey B, Bendriem B, Bouvier A, Lecomte $J \mathrm{~L}$, et al. Physical characterization of a time of flight positron emission tomography system for whole body quantitative studies. $f$ Nucl Med 1984; 25:46.

16 Pantano P, Baron JC, Crouzel C, Collard P, Sirou P Samson $\mathrm{Y}$. The ${ }^{15} \mathrm{O}$ continuous-inhalation method: cor-
rection for intravascular signal using $\mathrm{C}^{15} \mathrm{O}$. Eur $\mathcal{f} \mathrm{Nucl}$ Med 1985;10:387-91

17 Laplane D, Levasseur M, Pillon B, Dubois B, Baulac M, Mazoyer $\mathrm{B}$, et al. Obsession-compulsions and other behavioral changes with bilateral basal ganglia lesions: a neuropsychological, magnetic resonance imaging and positron emission tomography study. Brain 1989;112 699-725.

18 Matsui T, Hirano A. An atlas of the human brain for computerized tomography. Tokyo: Igaku-Shoin, 1978

19 Wredling $R$, Levander $S$, Adamson $U$, Lins $P E$ Permanent neuropsychological impairment after recurrent episodes of severe hypoglycaemia in man. Diabetologia 1990;33:152-7.

20 Bale RN. Brain damage in diabetes mellitus. $\mathrm{Br} f$ Psychiatry 1973;122:337-41.

21 Sachon C, Grimaldi A, Digy JP, Pillon B, Dubois B Thervet F. Cognitive function, insulin diabetes and hypoglycaemia. F Intern Med 1992;231:471-5.

22 Langan SJ, Deary IJ, Hepburn DA, Frier BM. Cumulative cognitive impairment following recurrent severe hypoglycaemia in adult patients with insulin-treated diabete mellitus. Diabetologia 1991;34:337-44.

23 Reichard P, Berglund A, Britz A, Levander S, Rosenqvist U. Hypoglycaemic episodes during intensified insulin treatment: increased frequency but no effect on cognitive function. $\mathcal{F}$ Intern Med 1991;229:9-16.

24 Baron JC, Frackowiak RSJ, Herholz K, Jones T, Samson Y, Bousser MG. Effects of thalamic stroke on energy metabolism of the cerebral cortex. A positron tomography study in man. Brain 1986;109:1243-59.

25 Blin J, Baron JC, Dubois B, Pillon B, Cambon $H$ Cambier J, et al. Positron emission tomography study in progressive supranuclear palsy. Brain hypometabolic progressive supranuclear palsy. Brain hypometabolic pattern and clinin

26 Frackowiak RSJ, Pozzili C, Legg NJ, Du Boulay GH, Marshall J, Lenzi GL. Regional cerebral oxygen utilization in dementia. A clinical study with oxygen-15 and positron emission tomography. Brain 1981;104:753-78.

27 Theodore WH, Dorwart R, Holmes M, Porter RJ, Dichiro G. Neuroimaging in refractory partial seizures: comparison of PET, CT and MRI. Neurology 1986;36:750-9.

28 Ryan CM, Williams TM, Finegold DN, Orchard TJ. Cognitive dysfunction in adult type I (insulin dependent) diabetes mellitus of long duration: effects of recurrent hypoglycaemia and other chronic complications. Diabetologia 1993;36:329-34.

29 Kalimo H, Olsson Y. Effects of severe hypoglycaemia on the human brain. Neuropathological case reports. Acta the human brain. Neuropatho Scand 1980;62:357-67.

30 Moersh FP, Kernohan J. Hypoglycaemia. Neurologic and neuropathologic studies. Archives of Neurology and Psychiatry 1939:242-57.

31 Anderson JM, Milner RDG, Strich SJ. Effects of neonatal hypoglycaemia on the nervous system: a pathological study. F Neurol Neurosurg Psychiatry 1967;30:295-310.

32 Iwai A, Sakamoto T, Kinoshita Y, Yokota J, Yoshioka T, Sugimoto $T$. Computed tomographic imaging of the brain in after hypoglycaemic coma. Neuroradiology 1987;29:398-400.

33 Turkinson RW. Encephalopathy induced by oral hypoglycaemic agents. Arch Intern Med 1977;137:1082-3.

34 Malouf R, Brust JCM. Hypoglycaemia: causes, neurological manifestations and outcome. Ann Neurol 1985;5: 421-30.

35 Grimaldi A, Bosquet F, Davidoff P, Digy J, Landault C, Thervet F, et al. Unawareness of hypoglycaemia by insulin-d

36 Auer RN, Kalimo H, Olsson Y, Siesjö BK. The temporal evolution of hypoglycaemic brain damage. 3. Light and electron microscopic findings in the rat caudoputamen. Acta Neuropathol (Berl) 1985;67:25-36.

37 Auer RN, Kalimo H, Olsson Y, Siesjö BK. The tempora evolution of hypoglycaemic brain damage. 1. Light and electron microscopic findings in the rat cerebral cortex Acta Neuropathol (Berl) 1985;67:13-24.

38 Auer RN, Kalimo H, Olsson Y, Siesjö BK. The tempora evolution of hypoglycaemic brain damage. 2. Light and electron microscopic findings in the hippocampal and subiculum of the rat. Acta Neuropathol (Berl) 1985; 67:25-36.

39 Auer RN, Wieloch T, Olsson Y, Siesjö BK. The distribution of hypoglycaemic brain damage. Acta Neuropathol (Berl) 1984;64:177-91.

40 Auer RN, Olsson Y, Siesjö BK. Hypoglycaemic injury in the rat. Correlation of density of brain damage with the EEG isoelectric time: a quantitative study. Diabetes 1984;33:1090-8.

41 Meldrum BS, Horton RW, Brierley JB. Insulin induced hypoglycaemia in the primate: relationship between physiological changes and neuropathology. In: Brierley Heinemann, 1971:207-24. 
42 Lapresle J, Milhaud $M$. Lesions du système nerveux central après arrêt circulatoire. Presse Med 1962;9:429-32.

43 Teruyashi Inoue, Hiroyuki Kato, Tsutomo Araki, Kyuga Kogure. Emphasized selective vulnerability after nonlethal cerebral ischemic insults in rats. Stroke 1992

44 Norberg K, Siesjö BK. Oxidative metabolism of the cerebral cortex of the rat in severe insulin-induced hypoglycaemia. F Neurochem 1976;26:345-52.

45 Ghajar JBG, Plum F, Duffy TE. Cerebral oxidative metab olism and blood flow during acute hypoglycaemia and recovery in unanesthetized rats. F Neurochem 1982; 30:397-409.

46 Auer RN, Siesiö BK. Biological differences between ischemia, hypoglycaemia and epilepsy. Ann Neurol 1988; 24:699-707.

47 Siesjö BK, Agardh CD. Hypoglycaemia. In: A Lajtha, ed. Handbook of neurochemistry. New York: Plenum, 1983; 3:353-79.

48 Della Porta P, Maiolo AT, Negri VU, Rossela E. Cerebral blood flow and metabolism in therapeutic insulin coma. Metabolism 1964;2:131-40. 